\title{
Basal metabolic rate and body composition of elite Japanese male athletes
}

\author{
Takako Koshimizu', Yoshiko Matsushima², Yukari Yokota ${ }^{3}$, Kae Yanagisawa ${ }^{4}$, \\ Satsuki Nagai ${ }^{5}$ Koji Okamura ${ }^{3}$, Yutaka Komatsu', and Takashi Kawahara ${ }^{6}$ \\ ${ }^{1}$ Faculty of Sports and Health Science, Fukuoka University, Fukuoka, Japan ; ${ }^{2}$ Department of Nutrition, \\ School of Health and Nutrition, Tokai Gakuen University, Aichi, Japan ; Graduate School of Sports \\ Science, Osaka University of Health and Sport Sciences, Osaka, Japan ; ${ }^{4}$ Faculty of Nutrition Science, \\ Sagami Women's University, Kanagawa, Japan ; ${ }^{5}$ Yokohama Minami Kyosai Hospital, Kanagawa, \\ Japan; and ${ }^{6}$ Department of Sports Medicine, Japan Institute of Sports Sciences, Tokyo, Japan
}

\begin{abstract}
The estimated energy requirement is important for adequate nutritional management in athletes. The energy requirement can be estimated from the basal metabolic rate (BMR). However, there is little data regarding the BMR of Japanese athletes. This study measured the BMR and body composition of 81 elite Japanese male athletes in different sports categories : endurance (E), strength, power and sprint (S) and ball game (B). The factors influencing the BMR were also investigated. The BMR and body composition were measured by indirect calorimetry and an air-displacement plentysmograph device (the BOD POD), respectively. The BMR per lean body mass (LBM) differed significantly among the three groups. The BMR was significantly correlated with the body weight (BW) and LBM in all groups. A multiple-regression analysis showed that the LBM was the most powerful predictor in the $E$ and $S$ groups, whereas the $B W$ was the most powerful predictor in the B group. The BW appears to become an important predictor as the BW of athletes increases. Additionally, height was the second explanatory variable in the $S$ and B groups, thus suggesting that height needs to be considered for the BMR in these groups. Therefore, the BMR in elite athletes needs to be estimated according to their body composition. J. Med. Invest. 59 : 253-260, August, 2012
\end{abstract}

Keywords : basal metabolic rate, elite male athletes, body composition, sports characteristics

\section{INTRODUCTION}

Adequate nutritional intake is an important factor for athletes to stay in good condition. For athletes to receive adequate nutritional management, it is important to draw up a Dietary Reference Intakes (DRIs) that serves as the criterion for evaluating the

Received for publication June 4, 2012 ; accepted July 20, 2012.

Address correspondence and reprint requests to Takako Koshimizu, M.S., R.D., Faculty of Sports and Health Science, Fukuoka University, 8-19-1 Nanakuma, Jyonan-ku, Fukuoka, 814-0180, Japan and Fax : +81-92-865-6029. amount of nutrient and energy intake an athlete requires. However, in the Dietary Reference Intakes for Japanese, 2005 (1) published by the Ministry of Health, Labour and Welfare, highly active athletes were not evaluated. It is thought that the BMR is more strongly correlated with the lean body mass (LBM) than the body weight (BW) (2-4). In addition, the LBM is usually greater in athletes compared to the average person. Therefore, Japan Institute of Sports Sciences (JISS : JISS offers support and research in sports science, medicine and information for Japanese top athletes' performance enhancement.) has used the LBM-based BMR 
(28.5 kcal/kg LBM, JISS equation) for evaluating elite athletes' estimated energy requirement (5). However, this value is calculated from the basal metabolic standard values for individuals aged 1829 years shown in DRIs and in the Japanese anthropometric reference data (JARD) of 2001 (6), rather than the actual measured values of elite athletes due to little data available regarding the BMR of elite athletes in Japan. DRIs for Japanese, 2010 (7) has reported that the combination of suitable body composition evaluations and the corresponding estimation equation would ensure more accurate measurements of BMR in the future.

In this study, we conducted actual measurements of the body composition and the BMR required to calculate the BMR in elite male athletes in the sport categories used in the JISS equation. In addition, we evaluated the factors that influence the BMR of elite male athletes.

\section{METHODS}

\section{Subjects}

Eighty-one elite male athletes who participated in various sports at the national team level in Japan volunteered for this study. We conducted our study during their normal training period. We categorized the elite athletes into the following three groups based on the characteristics of their sport used in the JISS equation (5) : an endurance sports group, $\mathrm{E}(\mathrm{n}=24)$, a strength, power and sprint sports group, $S(n=23)$ and a ball game group, $B(n=34)$. This categorization is shown in Table 1.

This study was conducted with the approval of the Japan Institute of Sports Sciences ethics committee. We explained the aims and significance of our study to the subjects and obtained their written informed consent prior to conducting the study.

\section{Measurement items}

\section{Body composition analysis}

The BW and height $(\mathrm{Ht})$ were measured with minimal clothing under fasting conditions after measurement of the BMR. The Ht was measured using an electronic stadiometer $(\mathrm{AD}-6225 \mathrm{~A} ; \mathrm{A} \& \mathrm{D}$ Co.,Ltd.,Tokyo,Japan). The body volume and BW were measured using an air-displacement plethysmograph device (the BOD POD, Life Measurment Inc.,USA) . The body density was calculated as the BW/body volume and the body fat percentage was calculated by using Brozek's equation (8). The LBM and body fat mass (FM) were calculated as the BW/body fat percentage.

Measurement of the BMR

The subjects had the same normal dinner at the accommodation by $18: 30$ and were instructed to drink only water thereafter. After an overnight fast at the accommodation where the room was maintained at a constant temperature of $20-25^{\circ} \mathrm{C}$, the subjects were quietly awakened between $06: 00$ and $07: 00$. Their body temperature and resting heart rate were then measured to confirm that they were in a resting state. Subjects remained awake in the supine position, and had a mask attached while remaining in bed for more than 15 minutes. A sample of expired air was collected in Douglas bags for a duration of 10 minutes. A mass spectrometer for respiratory analysis (ARCO-2000MASS SPECTROMETER) was used to analyze the oxygen and carbon dioxide concentrations and measure the ventilation. The gas exchange results were converted to the BMR (kcal/day) using Weir's equation (9). The BMR per BW (kcal/kg BW/day) and per LBM (kcal/kg LBM/day) were also calculated. Blood analysis

Venous blood samples were taken after the measurement of the BMR to analyze the haemoglobin

Table 1. Subjects events (Composition of each group)

\begin{tabular}{lll}
\multicolumn{1}{c}{$\begin{array}{c}\mathrm{E} \\
(\mathrm{n}=24)\end{array}$} & \multicolumn{1}{c}{$\mathrm{S}$} & \multicolumn{1}{c}{$\mathrm{B}$} \\
$(\mathrm{n}=23)$ & \multicolumn{1}{c}{$\mathrm{B}=34)$} \\
\hline Triathlon $(\mathrm{n}=3)$ & Snowboard Alpen $(\mathrm{n}=3)$ & Rugby football $(\mathrm{n}=15)$ \\
Rowing $(\mathrm{n}=5)$ & Boxing $(\mathrm{n}=4)$ & \\
Sailing Yacht $(\mathrm{n}=9)$ & Cycling Track short distance $(\mathrm{n}=6)$ & \\
Cycling Road $(\mathrm{n}=2)$ & Swimming Short distance $(\mathrm{n}=2)$ & \\
Cycling Track middle and long distance & Athletics Pole vault $(\mathrm{n}=1)$ & \\
$(\mathrm{n}=5)$ & Athletics Discus throw $(\mathrm{n}=2)$ & \\
& Athletics Javelin throw $(\mathrm{n}=2)$ & \\
& Athletics Decathlon $(\mathrm{n}=3)$ & \\
\hline
\end{tabular}


concentration $(\mathrm{Hb})$, serum ferritin ( $\mathrm{Fr}$ ), blood sugar (BS), serum triiodothyronine $\left(\mathrm{T}_{3}\right)$, serum thyroxine $\left(\mathrm{T}_{4}\right)$ and serum cortisol level. Hb was determined by the Sodium Lauryl Sulfate (SLS)-Hb assay and Fr was measured by a chemiluminescent enzyme immunoassay (CLEIA). BS was determined by the hexokinase-ultraviolet (HK-UV). $\mathrm{T}_{3}$ and $\mathrm{T}_{4}$ were determined by electrochemilumiescence immuno assay (ECLIA). Cortisol was determined by a radioimmuno assay (RIA).

Dietary survey and Physical activity record method

The dietary survey and physical activity record for three consecutive days prior to measurements of the BMR were recorded. The dietary survey consisted of a self-completed food record and digital photos of all foods consumed. Interviews were conducted by a registered dietician during admission to check the quantities and ingredients of the food. The dietary analysis was performed using a nutritional software program (e-diary JISS, Tokyo, Japan) to evaluate the energy and nutrient intakes. The selfcompleted time-study method was used to record all physical activities of the subjects for 3 days, and the total energy expenditure (TEE) was calculated. Statistical analysis

All results are expressed as the mean \pm standard deviation (SD). All of the statistical analysis were performed with the R(version 2.14.0 ; R Development Core Team (2011)) and Dr SPSS II for Windows (standard version ; SPSS.Inc.,Chicago,IL, USA) software program. The differences among the three groups were analyzed with a one-way analysis of variance (one-way ANOVA) techniques. The Bonferroni test was used when a significant difference was indicated by a one-way ANOVA. A stepwise multiple regression analysis for the BMR (dependent variable) was done using the possible independent variables of age, Ht, LBM, FM and $\mathrm{T}_{3}$. The relationship between the differences in the BMR and $\mathrm{BW}$, and BMR and LBM were examined using Pearson's correlation. Comparisons of the regression parameters techniques were used to compare the regression coefficients among the three groups. Statistical significance was set at $\mathrm{p}<0.05$ for all parameters.

\section{RESULTS}

The subjects' physical characteristics are shown in Table 2. Age was significantly older in the $\mathrm{S}$ group than in the B group. The Ht, BW and LBM were significantly higher in the $\mathrm{S}$ and $\mathrm{B}$ groups than in the E group. The body fat percentage was significantly lower in both the $\mathrm{S}$ and $\mathrm{B}$ groups than in the E group. There were no significant differences in FM among the three groups.

Table 3 shows the BMR in the three groups.

Table 2. Subjects characteristics

\begin{tabular}{cccccc}
\hline & & All & $\mathrm{E}$ & $\mathrm{S}$ & \\
$(\mathrm{n}=81)$ & $(\mathrm{n}=23)$ & $\begin{array}{c}\mathrm{B} \\
(\mathrm{n}=34)\end{array}$ \\
\hline Age & $\mathrm{y}$ & $21.4 \pm 3.0$ & $21.5 \pm 3.4^{\mathrm{b}}$ & $22.5 \pm 4.1^{\mathrm{a}}$ & $20.5 \pm 0.8^{\mathrm{b}}$ \\
$\mathrm{Ht}$ & $\mathrm{cm}$ & $175.6 \pm 5.6$ & $172.9 \pm 5.9^{\mathrm{a}}$ & $176.8 \pm 5.2^{\mathrm{b}}$ & $176.6 \pm 5.1^{\mathrm{b}}$ \\
BW & $\mathrm{kg}$ & $73.9 \pm 10.3$ & $67.6 \pm 6.2^{\mathrm{a}}$ & $74.4 \pm 10.3^{\mathrm{b}}$ & $78.1 \pm 10.7^{\mathrm{b}}$ \\
\%BF & $\%$ & $14.1 \pm 4.7$ & $16.3 \pm 3.8^{\mathrm{a}}$ & $13.1 \pm 4.2^{\mathrm{b}}$ & $13.3 \pm 5.3^{\mathrm{b}}$ \\
LBM & $\mathrm{kg}$ & $63.3 \pm 8.0$ & $56.4 \pm 4.5^{\mathrm{a}}$ & $64.5 \pm 8.5^{\mathrm{b}}$ & $67.3 \pm 6.5^{\mathrm{b}}$ \\
FM & $\mathrm{kg}$ & $10.6 \pm 4.7$ & $11.1 \pm 3.3$ & $9.9 \pm 4.0$ & $10.8 \pm 5.8$ \\
\hline
\end{tabular}

Values are means \pm SD.

Different letters are significant difference.

Table 3. The BMR of the subjects

\begin{tabular}{ccccc}
\hline & All & $\mathrm{E}$ & $\mathrm{S}$ & $\mathrm{B}$ \\
$(\mathrm{n}=81)$ & $(\mathrm{n}=24)$ & $1,783 \pm 269^{\mathrm{a}}$ & $1,986 \pm 300^{\mathrm{b}}$ \\
\hline $\mathrm{kcal} /$ day & $1,852 \pm 281$ & $1,729 \pm 171^{\mathrm{a}}$ & $24.0 \pm 2.1^{\mathrm{b}}$ & $25.5 \pm 1.9^{\mathrm{a}}$ \\
$\mathrm{kcal} / \mathrm{kg} \mathrm{BW} /$ day & $25.1 \pm 2.2$ & $25.7 \pm 2.4^{\mathrm{a}}$ & $27.7 \pm 2.2^{\mathrm{b}}$ & $29.5 \pm 2.8^{\mathrm{a}}$ \\
$\mathrm{kcal} / \mathrm{kg} \mathrm{LBM} /$ day & $29.3 \pm 2.8$ & $30.7 \pm 2.4^{\mathrm{a}}$ & $23)$ \\
\hline
\end{tabular}

Values are the means \pm SD.

Different letters represent a significant difference. 
There were significant differences among the three groups in the BMR in terms of $\mathrm{kcal} /$ day $(\mathrm{p}<0.01)$. The B group had significantly higher BMR values compared with the E group $(p<0.01)$ and the $S$ group $(p<0.05)$. There were significant differences among the three groups in the BMR in terms of $\mathrm{kcal} / \mathrm{kg} \mathrm{BW} /$ day $(\mathrm{p}<0.05)$. The value for the $\mathrm{S}$ group was significantly lower than that for the $\mathrm{E}$ group $(\mathrm{p}<0.05)$ and the B group $(\mathrm{p}<0.05)$. There were also significant differences among the three groups in the BMR in terms of the $\mathrm{kcal} / \mathrm{kg} \mathrm{LBM} /$ day $(p<0.01)$. The $S$ group had significantly lower values compared with both the E group $(\mathrm{p}<0.05)$ and $B$ group $(\mathrm{p}<0.05)$.

Figure 1 shows a significant correlation between the BW and BMR (kcal/day) for the E group ( $\mathrm{r}=$ 0.523, $\mathrm{p}<0.01)$, S group $(\mathrm{r}=0.821, \mathrm{p}<0.0001)$ and B group $(r=0.866, p<0.0001)$. Similarly, Figure 2 shows a significant correlations between the LBM and BMR (kcal/day) for the E group ( $\mathrm{r}=0.630, \mathrm{p}<$ 0.001), $S$ group $(r=0.824, p<0.0001)$ and $B$ group $(r=0.778, p<0.0001)$. A comparison of the regression lines for the BMR and $\mathrm{BW}(\mathrm{p}<0.01)$ and the

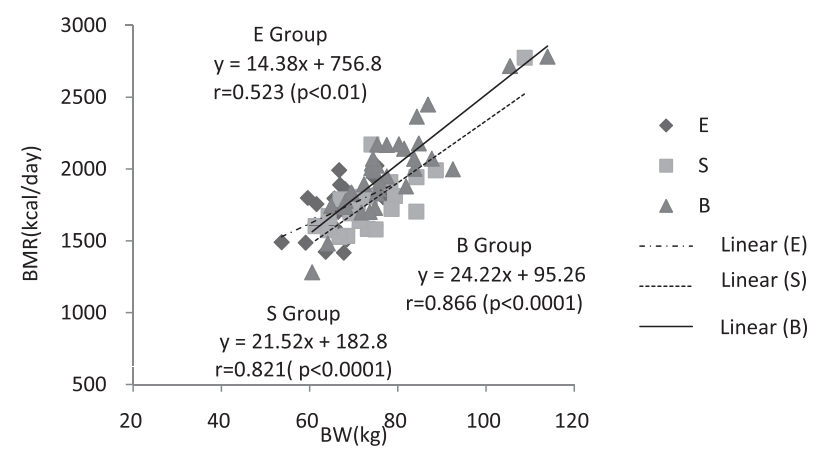

Figure 1 Relationship between BW and the BMR.

Correlation between BW and the BMR in the E, S and B group. A comparison of the regression lines for BW and BMR $(p<$ 0.001 ) revealed that there were significant differences in the intercepts among the three lines.

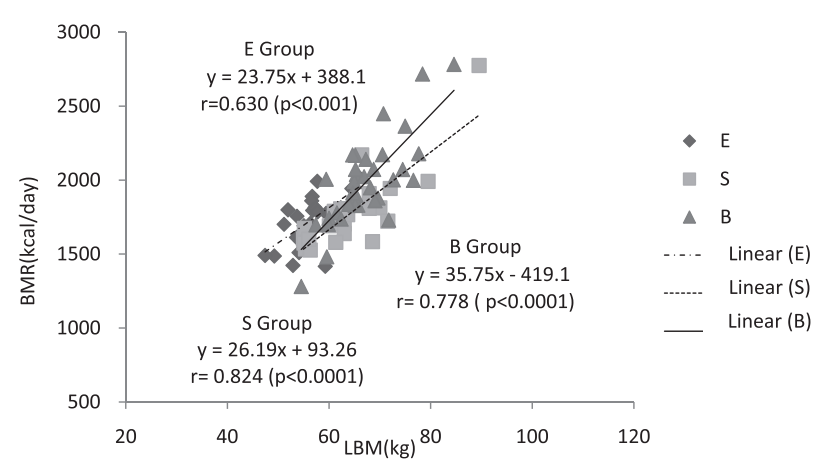

Figure 2 Relationship between LBM and the BMR.

Correlation between LBM and the BMR in the E, S and B group. A comparison of the regression lines for LBM and BMR $(\mathrm{p}<$ $0.05)$ revealed that there were significant differences in the intercepts among the three lines.
BMR and LBM $(\mathrm{p}<0.05)$, revealed that there were significant differences in the intercepts among the three groups. Namely, the each sports characteristics regression lines were significant difference, thus indicating that the BMR varied depending on the sports characteristics.

Tables $4-1,-2$ and -3 show the results of a stepwise multiple regression analysis for the BMR

Table 4-1 Stepwise multiple regression analysis of BMR as an independent variable (E group)

\begin{tabular}{cccccc}
\hline \multicolumn{2}{c}{ variable } & B & SEB & $\beta$ & r \\
\hline \multicolumn{2}{c}{ Step1 } & & & & \\
LBM & & 23.746 & 6.242 & $0.630^{*}$ & .630 \\
& SEE & 136.007 & & & \\
& $\mathrm{R}^{2}$ & .397 & & & \\
\hline
\end{tabular}

${ }^{*}: \mathrm{p}<0.001$

Table 4-2 Stepwise multiple regression analysis of BMR as an independent variable (S group)

\begin{tabular}{|c|c|c|c|c|c|}
\hline & variable & B & SEB & $\beta$ & $\mathrm{r}$ \\
\hline \multicolumn{6}{|c|}{ Step1 } \\
\hline \multirow[t]{3}{*}{ LBM } & & 26.192 & 3.932 & $0.824^{*}$ & .824 \\
\hline & SEE & 156.022 & & & \\
\hline & $\mathrm{R}^{2}$ & .679 & & & \\
\hline \multicolumn{6}{|c|}{ Step2 } \\
\hline LBM & & 20.023 & 4.954 & $0.63^{\star *}$ & .824 \\
\hline $\mathrm{Ht}$ & & 15.055 & 7.999 & $0.293 * \star$ & .710 \\
\hline & SEE & 147.358 & & & \\
\hline & $\mathrm{R}^{2}$ & .727 & & & \\
\hline & $\Delta \mathrm{R}^{2}$ & .048 & & & \\
\hline
\end{tabular}

Table 4-3 Stepwise multiple regression analysis of BMR as an independent variable (B group)

\begin{tabular}{|c|c|c|c|c|c|}
\hline & variable & B & SEB & $\beta$ & $r$ \\
\hline \multicolumn{6}{|c|}{ Step1 } \\
\hline \multirow[t]{3}{*}{ BW } & & 24.231 & 2.473 & $0.866^{\star *}$ & .866 \\
\hline & SEE & 152.432 & & & \\
\hline & $\mathrm{R}^{2}$ & .750 & & & \\
\hline \multicolumn{6}{|c|}{ Step2 } \\
\hline BW & & 26.332 & 2.782 & $0.941^{* *}$ & .866 \\
\hline $\mathrm{Ht}$ & & -8.899 & 5.801 & $-0.153^{* *}$ & .311 \\
\hline & SEE & 149.308 & & & \\
\hline & $\mathrm{R}^{2}$ & .768 & & & \\
\hline & $\Delta \mathrm{R}^{2}$ & 0.018 & & & \\
\hline
\end{tabular}

** $: \mathrm{p}<0.0001$

$B$ : Standarised regression crefficient, SEB : Standard error of regression coefficient.

$\beta$ : Standarised partial regression coefficient, $r$ : correlation coefficient.

$\mathrm{SEE}$ : Standard error of estimated value, $\mathrm{R}^{2}$ : Coefficient of determination.

$\Delta \mathrm{R}^{2}$ : Increment of $\mathrm{R}^{2}$. 
(dependent variable) with the subject's age, Ht, BW, LBM, FM and $\mathrm{T}_{3}$ as possible independent variables. The LBM accounted for 39.7\% of the BMR in the $\mathrm{E}$ group and the standard error of the estimated value was $136 \mathrm{kcal} / \mathrm{day}$. For the S group, the LBM and Ht accounted for $72.7 \%$ of the variable, with a standard error of the estimated value of $147 \mathrm{kcal} /$ day. For the B group, the BW and Ht accounted for $76.8 \%$, with a standard error of the estimated value of $149 \mathrm{kcal} /$ day.

Table 5 shows the results of a blood analysis. All data for the three groups were within the normal ranges, and there were no significant differences among them.

Table 6 shows the nutrient intakes and TEE of the subjects. The TEE did not differ significantly among the three groups. However, the energy, protein and carbohydrate intakes per BW were significantly higher in the E group than in the S and $\mathrm{B}$ groups $(\mathrm{p}<0.01)$. The protein and calcium intakes $(\mathrm{p}<0.01)$ and vitamin $\mathrm{A}$ and vitamin $\mathrm{C}$ intakes $(\mathrm{p}<$ 0.05 ) were significantly higher in the $\mathrm{E}$ group than in the B group. No correlations were observed between the amounts of energy intake and nutrient intakes and the BMR in any of the groups.

\section{DISCUSSION}

It has been reported that after exercise, excess post-exercise oxygen consumption (EPOC) is remarkably induced after 80 minutes of exercise at the intensity of $70 \%$ of the maximal oxygen uptake $\left(\mathrm{VO}_{2} \mathrm{max}\right)$ and that the resting metabolic rate (RMR) increases during the next 24 hours(10). However, no increase in the RMR was reported for 24 hours after 30 minutes of exercise at $70 \% \mathrm{VO}_{2} \max (11)$, indicating that the effect of EPOC varies depending

Table 5. Results of the blood analyses

\begin{tabular}{cccccc}
\hline & & All & $\mathrm{E}$ & $\mathrm{S}$ & $\mathrm{B}$ \\
$(\mathrm{n}=81)$ & $(\mathrm{n}=24)$ & $153)$ & $15.4 \pm 0.7$ \\
$\mathrm{Hb}$ & $\mathrm{g} / \mathrm{dl}$ & $15.5 \pm 0.8$ & $15.5 \pm 0.8$ & $15.6 \pm 1.0$ & $74.1 \pm 39.6$ \\
$\mathrm{Fr}$ & $\mathrm{ng} / \mathrm{dl}$ & $75.0 \pm 36.6$ & $63.9 \pm 33.2$ & $87.9 \pm 32.5$ & $88 \pm 9$ \\
$\mathrm{BS}$ & $\mathrm{mg} / \mathrm{dl}$ & $89 \pm 7$ & $89 \pm 7$ & $90 \pm 5$ & $1.20 \pm 0.15$ \\
$\mathrm{~T} 3$ & $\mathrm{ng} / \mathrm{ml}$ & $1.15 \pm 0.16$ & $1.11 \pm 0.15$ & $1.12 \pm 0.16$ & $7.4 \pm 1.0$ \\
$\mathrm{~T}_{4}$ & $\mu \mathrm{g} / \mathrm{dl}$ & $7.6 \pm 1.1$ & $7.7 \pm 1.1$ & $7.9 \pm 1.1$ & $25.2 \pm 6.1$ \\
Cortisol & $\mu \mathrm{g} / \mathrm{dl}$ & $23.3 \pm 7.0$ & $23.4 \pm 7.5$ & $20.6 \pm 7.3$ & \\
\hline
\end{tabular}

Values are means \pm SD.

Table 6. Daily energy expenditure and daily energy and nutritional intakes

\begin{tabular}{|c|c|c|c|c|c|}
\hline & & $\underset{(n=81)}{\text { All }}$ & $\begin{array}{c}\mathrm{E} \\
(\mathrm{n}=24)\end{array}$ & $\begin{array}{c}\mathrm{S} \\
(\mathrm{n}=23)\end{array}$ & $\underset{(n=34)}{\text { B }}$ \\
\hline \multirow[t]{2}{*}{ Energy intakes } & kcal & $3,284 \pm 662$ & $3,520 \pm 757$ & $3,118 \pm 613$ & $3,230 \pm 592$ \\
\hline & $\mathrm{kcal} / \mathrm{kg} \mathrm{BW}$ & $45.2 \pm 10.5$ & $52.2 \pm 10.5^{\mathrm{a}}$ & $42.2 \pm 7.4^{\mathrm{b}}$ & $42.3 \pm 10.3^{b}$ \\
\hline \multirow[t]{2}{*}{ Energy expenditure } & kcal & $4,595 \pm 982$ & $4,403 \pm 1,371$ & $4,680 \pm 837$ & $4,675 \pm 723$ \\
\hline & $\mathrm{kcal} / \mathrm{kg} \mathrm{BW}$ & $62.7 \pm 13.6$ & $65.1 \pm 19.0$ & $63.4 \pm 11.3$ & $60.5 \pm 10.1$ \\
\hline \multirow{2}{*}{ Protein } & $\mathrm{g}$ & $117.7 \pm 27.3$ & $132.5 \pm 28.0^{\mathrm{a}}$ & $113.7 \pm 30.1^{\mathrm{a}}$ & $109.9 \pm 20.5^{b}$ \\
\hline & $\mathrm{g} / \mathrm{kg} \mathrm{BW}$ & $1.6 \pm 0.4$ & $2.0 \pm 0.4^{\mathrm{a}}$ & $1.5 \pm 0.4^{\mathrm{b}}$ & $1.4 \pm 0.3^{\mathrm{b}}$ \\
\hline Fat & $\mathrm{g}$ & $108.5 \pm 32.5$ & $117.1 \pm 40.9$ & $102.3 \pm 31.1$ & $106.6 \pm 25.7$ \\
\hline \multirow{2}{*}{ Carbohydrate } & $\mathrm{g}$ & $441.7 \pm 105.1$ & $477.7 \pm 124.1$ & $420.8 \pm 5.7$ & $430.4 \pm 5.6$ \\
\hline & $\mathrm{g} / \mathrm{kg} \mathrm{BW}$ & $6.1 \pm 1.7$ & $7.1 \pm 1.7^{\mathrm{a}}$ & $5.7 \pm 1.3^{\mathrm{b}}$ & $5.6 \pm 1.6^{\mathrm{b}}$ \\
\hline Calcium & $\mathrm{mg}$ & $702 \pm 369$ & $825 \pm 434^{\mathrm{a}}$ & $800 \pm 404^{\mathrm{a}}$ & $549 \pm 217^{b}$ \\
\hline Iron & $\mathrm{mg}$ & $10.9 \pm 3.5$ & $12.9 \pm 3.8$ & $10.9 \pm 4.2$ & $9.3 \pm 1.8$ \\
\hline Vitamin A & $\mu g R E$ & $1,198 \pm 932$ & $1,548 \pm 1,143^{a}$ & $1,230 \pm 1,121^{\mathrm{a}}$ & $928 \pm 439^{b}$ \\
\hline Vitamin $B_{1}$ & $\mathrm{mg}$ & $2.44 \pm 2.72$ & $2.86 \pm 2.21$ & $3.15 \pm 4.42$ & $1.67 \pm 0.62$ \\
\hline Vitamin $B_{2}$ & $\mathrm{mg}$ & $2.87 \pm 4.16$ & $3.05 \pm 2.23$ & $4.10 \pm 7.33$ & $1.90 \pm 0.71$ \\
\hline Vitamin C & $\mathrm{mg}$ & $227 \pm 249$ & $331 \pm 367^{\mathrm{a}}$ & $264 \pm 210^{\mathrm{a}}$ & $129 \pm 96^{\mathrm{b}}$ \\
\hline
\end{tabular}

Values are means \pm SD.

Different letters indicate a significant difference. 
on the exercise conditions. It is extremely difficult for elite athletes who undergo daily training to rest more than one day. Since many elite athletes train more or less every day, it is reasonable to consider that the BMR for elite athletes includes EPOC. Therefore, we did not restrict their routine training during the study period. To measure the RMR, Compher et al. (12) indicated that healthy adults should abstained from moderate aerobic and anaerobic exercises for two hours before measurement and vigorous resistance exercise for at least 14 hours before measurement. In our study, we permitted our subjects to do their normal daily training until no less than 3 hours before their visit and ensured that they had enough rest the night before the measurement of the BMR. Furthermore, it is accepted that one measurement is adequate for determining the BMR. Although the accuracy of measurements would have improved if we conducted measurements two to three times non-consecutively, it is difficult for elite athletes who are busy with daily training to take time off for the measurements. Therefore, in this study, the measurement of BMR was conducted once.

We observed that the BMR was significantly correlated with both the LBM and BW in all groups (Figs. 1 and 2). In addition, the regression equations for both the BMR and LBM, and for the BMR and BW showed that the equation intercepts were significantly different for each of the intercepts according the type of sports characteristics. Although previous studies have suggested that no differences exist regarding the equation intercepts among the subjects depending on the type of sports characteristics $(13,14)$, the result of our current study contradicted these previous studies. In the previous studies, body composition was found to have a large effect on the BMR $(2,15,16)$. In the present study, one factor for significant differences in the regression intercepts for each sports characteristic is considered to be due to significant differences in body composition among these sports characteristics.

In this study, we examined elite athletes involved in 14 sporting events with a wide range of body compositions ; Ht : $159.0-187.3 \mathrm{~cm}$, BW : 53.7-113.9 $\mathrm{kg}$, percentage of body fat : $4.2-25.7 \%$ and LBM : $47.4-89.5 \mathrm{~kg}$. Body composition has been found to have an effect on sports performance $(17,18)$. In addition, it has been shown that the body composition varies depending on the specific characteristics of the sports that are being played $(19,20)$. The elite athletes' physiques were significantly larger in the $\mathrm{S}$ and $\mathrm{B}$ groups compared with the E group. Sports events categorized in the $\mathrm{S}$ and $\mathrm{B}$ groups require a larger amount of power in a shorter period of time. For example, more weight is considered be advantageous in some ball games such as rugby. Therefore, these elite athletes intentionally increase their weight with LBM.

It has been reported that a LBM has a greater effect on the BMR compared to the overall BW (24). The BMR per LBM was reported to not be significantly different between trained and untrained subjects $(21,22)$. However, in our results, the BMR per LBM in the S group was significantly lower than those in the E and B groups. Midorikawa et al. (23) suggested that not only skeletal muscle but also other fat free mass such as the liver and kidneys, is increased in resistance and/or high intensity trained athletes. The fat free mass is large and the resting energy expenditure (REE) is high in Sumo wrestlers compared to non-athletes. The high REE for Sumo wrestlers can be attributed not to an elevation of the organ-tissue metabolic rate, but to an increase in the absolute amount of both metabolically low tissues such as skeletal muscle and metabolically high tissues including the liver and kidneys (24). For such a reason, the low BMR per LBM for the elite athletes in the S group could have been the low weight increase of visceral organs, although whether this was the case was unclear from our present results.

A stepwise multiple regression analysis was performed to identify variables that may affect the BMR. We found that the BMR in the $\mathrm{E}$ and $\mathrm{S}$ groups was most dependent on the LBM, while in the B group, the BMR was most dependent on the BW. Therefore, it appears that the BMR depends on the BW rather than the LBM as the BW increases. Taguchi et al. (13) reported that the $\mathrm{T}_{3}$ level was an explanatory variable for the BMR in addition to the LBM in female athletes. In the present study, $\mathrm{T}_{3}$ level was not an explanatory variable in any of the three groups. However, in addition to the LBM, the subject's Ht was a second explanatory variable in the $\mathrm{S}$ and B groups. Heymsfield et al. (25) reported that the REE per BW was lower in taller subjects compared with shorter subjects due to the smaller mass of metabolically high tissue per BW in the taller subjects compared to the shorter subjects. Therefore, $\mathrm{Ht}$ is considered to be an important explanatory variable for determining the BMR in sporting events characterized by subjects of a taller height.

Yamamoto et al. (26) reported that it is necessary to investigate the relevance of sporting events 
and body composition on the BMR to establish a standard value of the BMR for athletes. The present study showed that body composition varies among sporting events. We therefore conclude that body composition should be considered to estimate the BMR in elite athletes according to their sporting events.

\section{CONFLICT OF INTERESTS}

None of the authors have any conflicts of interest to declare.

\section{ACKNOWLEDGEMENTS}

I would like to thank Japan Institute of Sports Sciences project research for a grant that made it possible to complete this study.

\section{REFERENCES}

1. Ministry of Health, Labour and Welfare : 2005 Dietary Reference Intakes for Japanese. Daiichi Shuppan Publishing Co., Ltd., Tokyo, 2005

2. Tataranni PA, Ravussin E : Variability in metabolic rate biological sites of regulation. Int $\mathrm{J}$ Obesity 19 : S102-106, 1995

3. Ravussin E, Bogardus C : Relationship of genetics, age, and physical fitness to daily energy expenditure and fuel utilization. Am J Clin Nutr 49 : 968-975, 1989

4. Fukagawa NK, Bandini LG, Young JB : Effect of age on body composition and resting metabolic rate. Am J Physiol 259 : E233-238, 1990

5. Koshimizu T, Yanagisawa K, Higuchi M : Estimated energy requirements in Japanese elite athletes. J Training Science for Exercise and Sport 17 : 245-250, 2005 (In Japanese)

6. Japanese Society of Nutritional Assessment : Japanese Anthropometric Reference Data: JARD2001. Japanese J Nutritional Assessment 19 (suppl), 2002

7. Ministry of Health, Labour and Welfare : 2010 Dietary Reference Intakes for Japanese. Daiichi Shuppan Publishing Co., Ltd., Tokyo, 2010

8. Brozek J, Grande EF, Anderson JT, Keys A : Densitometric analysis of body composition revision of some quantitative assumptions. Ann New York Acad Sci 110 : 113-140, 1963
9. Weir JB : New methods for calculating metabolic rate with special reference to protein metabolism. J Physiol 109 : 1-9, 1949

10. Maehlum S, Grandmontagne M, Newsholme EA, Sejersted OM : Magnitude and duration of exercise post-exercise oxygen consumption in healthy young subjects. Metabolism 35(5) : 425-429, 1986

11. Almuzaini KS, Potteiger JA, Green SB : Effects of split exercise sessions on excess post-exercise oxygen consumption and resting metabolic rate. Can J Appl Physiol 23(5) : 433-443, 1998

12. Compher C, Frankenfield D, Keim N, RothYousey L: Best practice methods to apply to measurement of resting metabolic rate in adults : A systematic review. J Am Diet Assoc $106: 881-903,2006$

13. Taguchi M, Tatsuta W, Higuchi M : Resting energy expenditure of female athletes in different type of sport. Jpn J Nutr Diet 68(5) : 289-297, 2010

14. Kashimura O, Nakai S, Yoshida T, Ito T: Basal metabolic rates in various kinds of sports. Japanese J Hygiene 42 : 809-814, 1987

15. Henry CJ : Mechanisms of changes in basal metabolism during ageing. Eur J Clin Nutr $54:$ S77-91, 2000

16. Paolosso G, Gambardella A, Balbi V, Ammendoka S, D'Amore A, Varricchio M : Body composition, body fat distribution, and resting metabolic rate in healthy centenarians. Am J Clin Nutr 62 : 746-750, 1995

17. Arrese AL, Ostariz ES : Skinfold thicknesses associated with distance running performance in highly trained runners. J Sports Sci 24(1) : 69-76, 2006

18. Knechtle B, Knechtle P, Rust CA, Rosemann $\mathrm{T}$ : Leg skinfold thicknesses and race performance in male 24-hour ultra-marathoners. Proc (Bayl Univ Med Cent) 24(2) : 110-114, 2011

19. Fleck SJ : Body composition of elite American athletes. Am J Sports Med 11(6) : 398-403, 1983

20. Musaiger AO, Ragheb MA, AL-Marooq G : Body composition of athletes in Bahrain. $\mathrm{Br} \mathrm{J}$ Sports Med 28(3) : 157-159, 1994

21. Taguchi M, Higuchi M, Oka J, Yoshiga C, Ishida $\mathrm{Y}$, Matsushita $\mathrm{M}$ : Basal metabolic rate in Japanese female athletes. Jpn J Nutr Diet 59(3) : 127-134, 2001

22. Takahashi E, Usui C, Tabata I, Higuchi $\mathrm{M}$ : Basal metabolic rate can be easily and accurately 
estimated by measuring of LBM in young female. J Training Sci. Exercise and Sport 20 (1) : 25-31, 2008

23. Midorikawa T, Sekiguchi O, Beekley MD, Bemben MG, Abe T : A comparison of organtissue level body composition between collegeage male athletes and non athletes. Int J Sports Med $28: 100-105,2006$

24. Midorikawa T, Kondo M, Beekley MD, Koizumi $\mathrm{K}$, Abe T: High REE in sumo wrestlers attributed to large organ-tissue mass. Med Sci Sports
Exerc 39(4) : 688-693, 2007

25. Heymsfield SB, Childers D, Beetsch J, Allison DB, Pietrobelli A : Body size and human energy requirements : reduced mass-specific resting energy, expenditure in tall adults. J Appl Physiol 103 : 1453-1550, 2007

26. Yamamoto S, Ishikawa-Takata K, Bessyo K, Tanimoto M, Miyachi M, Tanaka S, Totani M, Tabata I : Basal metabolic rate and physical activity level in bodybuilders. Jan J Nutr Diet 66 (4) : 195-200, 2008 